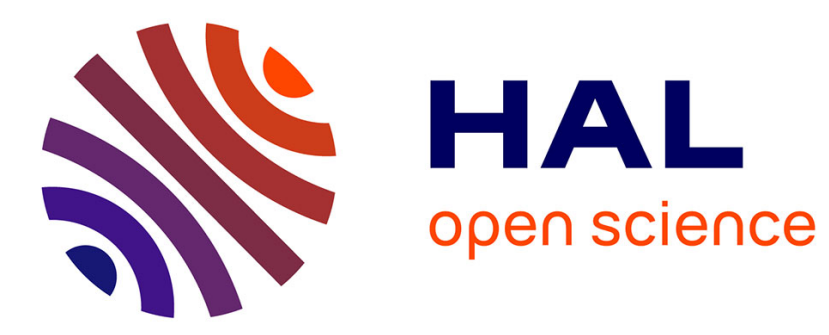

\title{
Integrated passively modelocked InGaAsP ringlasers with active-passive integration
}

Yohan Barbarin, E.A.J.M. Bente, M.J.R. J R Heck, J H den Besten, G. Guidi, M.K. K Smit, J.J.M. J M Binsma

\section{- To cite this version:}

Yohan Barbarin, E.A.J.M. Bente, M.J.R. J R Heck, J H den Besten, G. Guidi, et al.. Integrated passively modelocked InGaAsP ringlasers with active-passive integration. Integrated Photonics Research, 2004, San Francisco, United States. pp.IWC2, 10.1364/IPR.2004.IWC2 . hal-02550250

\section{HAL Id: hal-02550250 \\ https://hal.science/hal-02550250}

Submitted on 22 Apr 2020

HAL is a multi-disciplinary open access archive for the deposit and dissemination of scientific research documents, whether they are published or not. The documents may come from teaching and research institutions in France or abroad, or from public or private research centers.
L'archive ouverte pluridisciplinaire HAL, est destinée au dépôt et à la diffusion de documents scientifiques de niveau recherche, publiés ou non, émanant des établissements d'enseignement et de recherche français ou étrangers, des laboratoires publics ou privés. 


\title{
Integrated passively modelocked InGaAsP ringlasers with active-passive integration
}

\author{
Y. Barbarin, E.A.J.M. Bente, M.J.R. Heck, J.H. den Besten, G. Guidi and M.K. Smit \\ COBRA, Eindhoven University of Technology Den Dolech 2, P.O. Box 513, 5600 MB, Eindhoven, The Netherlands \\ y.barbarin@tue.nl
}

J.J.M. Binsma

JDS Uniphase, Prof. Holstlaan 4, NL-5656 AA, Eindhoven, The Netherlands

\begin{abstract}
Integrated modelocked ring lasers with fundamental repetition rates of 35 and $26 \mathrm{Ghz}$ were fabricated in InGaAsP using active-passive integration. First measurements shows pulses down to 1.2 ps width can be produced.

OCIS codes: (130.3120) Integrated optics devices; (140.5960) Semiconductor lasers; (140.4050) Mode-locked lasers (140.7090) Ultrafast lasers
\end{abstract}

\section{Introduction}

In this paper we present the first results from integrated passively modelocked InGaAsP ringlasers that we have fabricated. These devices are, to our knowledge, the first integrated passively modelocked ringlasers realised using an active-passive integration scheme [1]. This work is part of a project in which we are developing an All Optical Clock Recovery (AOCR) device based on an injection seeded passively ModeLocked Laser (MLL). For this application the ring configuration has two advantages. Firstly, the repetition rate of the laser is controlled accurately by photolithography as opposed to a device with cleaved facet mirrors. Secondly the ring laser configuration is more suitable for the injection seeding process that is at the centre of the AOCR. The butt-joint active-passive integration technology we have used makes the laser design suitable for further integration with other devices, e.g. a wavelength convertor [2].

\section{Design}

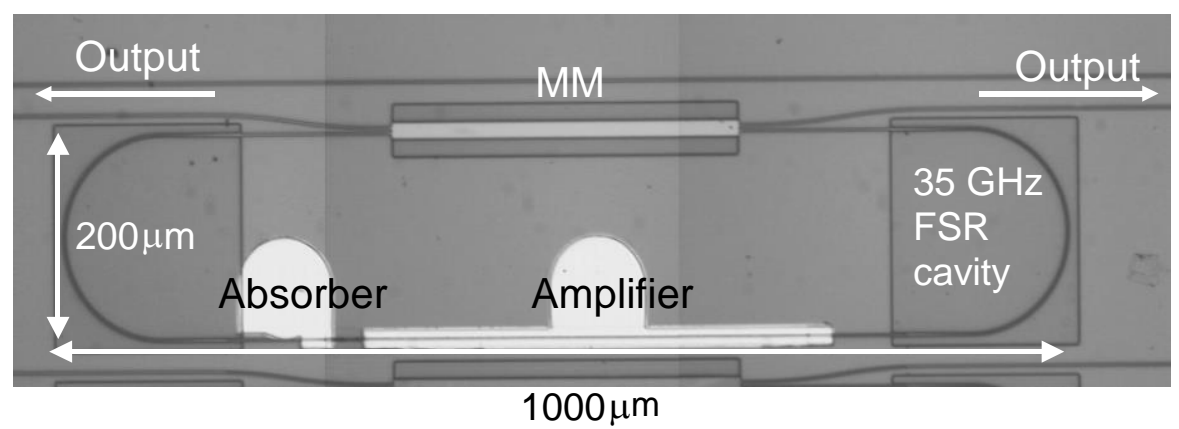

Fig.1: Optical microscope image of a part of the fabricated chip with a 35GHz MLL.

The different device designs have been realised in the InP/InGaAsP material system with active-passive integration. A picture of a fabricated $35 \mathrm{GHz}$ MLL is given in figure 1; waveguides are visible as dark lines. Light is coupled out from the oval shaped cavity using a Multi-Mode Interferometer (MMI). Opposite to the MMI an active region - a bulk Semiconductor Optical Amplifier (SOA) - is integrated in the passive cavity. The SOA is divided into two sections. Each can be contacted using the two bright metal pads visible in figure 1. The long section is a forward biased amplifier. The short section is a reverse biased saturable absorber. A short non-contacted section isolates the amplifier from the absorber $(\mathrm{R}=600 \mathrm{k} \Omega$ ). The Free Spectral Range (FSR) of the cavity corresponds to the required repetition rates of the laser.

The shallowly etched straight waveguides, the amplifier and the absorber in the MLL are $2 \mu \mathrm{m}$ wide in order to minimise propagation loss. Curved waveguides with a bending radius of $100 \mu \mathrm{m}$ are $1.7 \mu \mathrm{m}$ wide and deeply etched. The deep-shallow transition is made gradually using a $50 \mu \mathrm{m}$ long taper. An improvement in coupling is obtained by using an extra width of $0.3 \mu \mathrm{m}$ between the taper and the shallowly etched waveguide. To reduce facet reflectivity, the output waveguides (not visible in the figure 1) are angled by $7^{\circ}$ with respect to the facets normal. Since at this 
angle only the reflection from zero-order to zero-order mode is minimal, a mode filter is inserted to suppress the first-order mode [3], which can be guided by the SOA.

\section{Fabrication.}

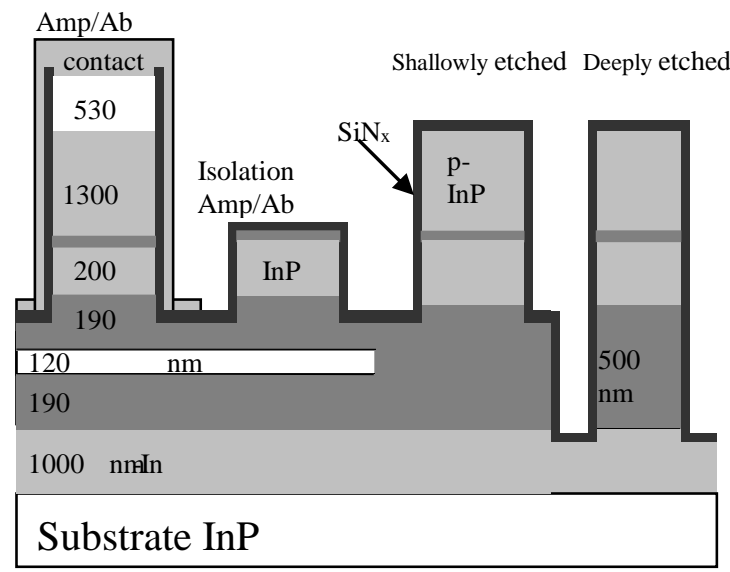

Fig.2: Cross-sections of amplifier, isolation, shallowly etched waveguides and deeply etched waveguides

All epitaxial layers for the MLL were grown by Low-Pressure Metal-Organic Vapour Phase Epitaxy (LP-MOVPE) at $625^{\circ} \mathrm{C}$. The SOA active layer consists of a $120 \mathrm{~nm}$ thick $\lambda=1.5 \mu \mathrm{m}$ InGaAsP layer between two $\lambda=1.25 \mu \mathrm{m}$ InGaAsP layers. The structure was covered by a 200 -nm-thick p-InP layer. Next, the active layer stack was butt joint to a $\lambda=1.25 \mu \mathrm{m}$ InGaAsP layer for the passive sections described in [4]. In the third epitaxy step, a 1300 -nm thick p-InP cladding layer and the $\mathrm{p}$-InGaAs contacting layer were grown.

A $70 \mathrm{~nm}$ thick PECVD-SiN layer served as an etching mask for the waveguides. The pattern was defined using contact photolithography with positive photoresist and transferred to the SiNx layer by $\mathrm{CHF}_{3}$ Reactive Ion Etching (RIE). Waveguides were etched in three steps employing an optimised $\mathrm{CH}_{4}-\mathrm{H}_{2}$ etching process (RIE). The isolation between the amplifier and the absorber in the SOA structure was realised wet chemical etching. The amplifier and the absorber were passivated with a $350 \mathrm{~nm}$ thick PECVD-SiN layer before the metalisation step. A further description of the fabrication can be found in [5].

\section{Experimental setup and first measurements}

The chip was soldered on a temperature controlled copper mount. The current and the reverse bias voltage were applied through two probes. Light from the two laser output waveguides was collected using lensed fibres and led to a spectrum analyser, power meters or an optical autocorrelator. In order to obtain autocorrelator traces, the signal needed to be amplified using an EDFA. The first results of two of our new devices are presented here. The devices are switched on by first turning up the current in the amplifier when the absorber is not connected. Then when the laser is above threshold the absorber is connected and a voltage is applied.

The first device has amplifier that is $670 \mu \mathrm{m}$ long; the absorber is $50 \mu \mathrm{m}$ long and the isolation section is $30 \mu \mathrm{m}$ long. The device was operated at $15^{\circ} \mathrm{C}$. The threshold current is around $90 \mathrm{~mA}$. The device is truly bi-directional and outputs powers, from the lensed fibres (4-5dB coupling loss), go up to $-5 \mathrm{dBm}$ at $120 \mathrm{~mA}$. The details in the output of the laser are highly dependent on the amplifier current. An example of a spectrum at $133 \mathrm{~mA}$ current in the amplifier is plotted in figure 3. There are two groups of four modes spaced by 8 FSR, other modes in the spectrum contain less power. The laser produces more than one pulse per roundtrip as can be seen from the autocorrelator trace (Fig. 5a). Pulses of $1.2 \mathrm{ps}$ duration at $26 \mathrm{Ghz}$ are generated together with less intense pulses in between. Using the recorded output spectrum we have calculated the field and the autocorrelation signal, assuming locked phases between modes. The calculated autocorrelation trace is plotted in figure $5 \mathrm{~b}$. The good matching between the measured and calculated autocorrelator traces shows that the system is stable with many pulses and does not switch between two frequencies. The mode structure of the cavity is under investigation, taking into account the small reflections at the different interfaces, e.g. the active-passive interfaces. 


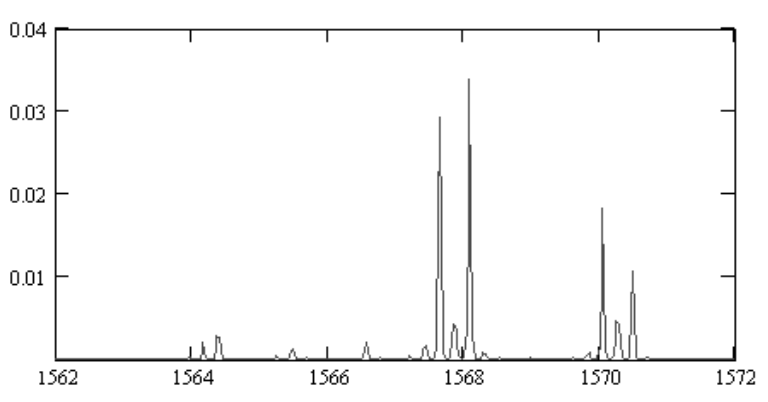

Fig. 3 Spectrum of a $26 \mathrm{GHz}$ dèvice $\mathrm{I}=133 \mathrm{~mA} \mathrm{~V}=-0.3 \mathrm{~V}$.
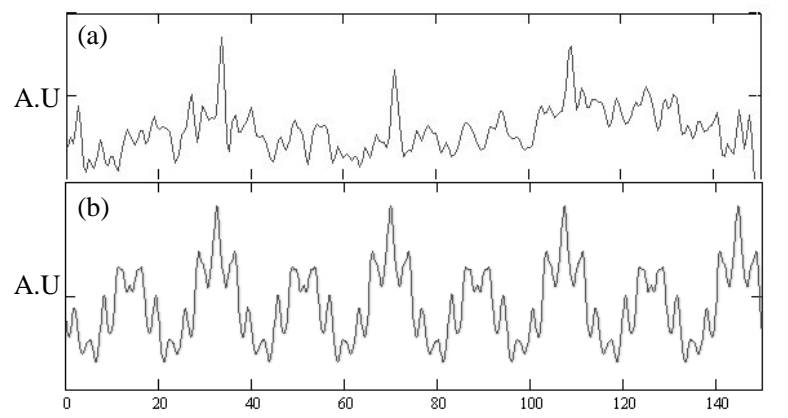

Fig. 5 (a) Measured autocorrelator trace at $26 \mathrm{GHz}$. (b) Calculated autocorrelator signal.

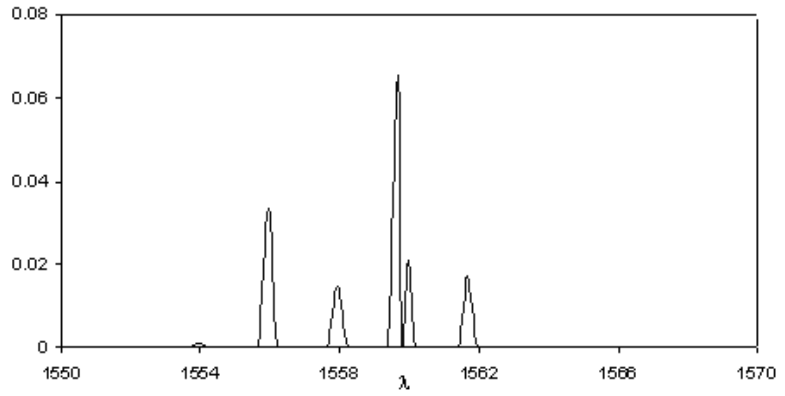

Fig. 4 Spectrum of a $35 \mathrm{GHz}$ device $\mathrm{I}=111 \mathrm{~mA} \mathrm{~V}=-0.8 \mathrm{~V}$.

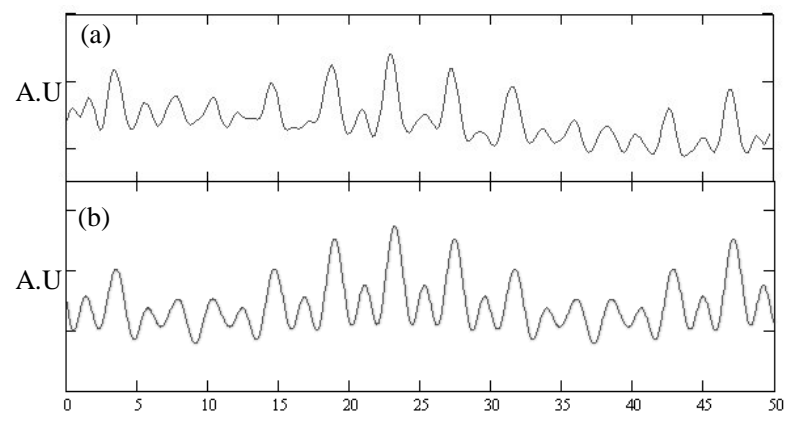

Fig. 6 (a) Measured autocorrelator trace at $35 \mathrm{GHz}$. (b) Calculated autocorrelator signal.

The second device reported here has a $440 \mu \mathrm{m}$ long forward biased amplifier, a $30 \mu \mathrm{m}$ long reverse biased saturable absorber and a $30 \mu \mathrm{m}$ long non-biased isolation section. Its repetition rate is $35 \mathrm{GHz}$. Due to the shorter amplifier in this device, it needs to be cooled down to $8^{\circ} \mathrm{C}$ in order to have sufficient gain to bleach the absorber. The threshold current is around $100 \mathrm{~mA}$. The device also operates bi-directionally and outputs power levels recorded in the fibres go up to $-6 \mathrm{dBm}$ at $110 \mathrm{~mA}$. The spectrum at $111 \mathrm{~mA}$ is plotted in figure 4 . There is one group of 4 modes and a second group of 2 modes with the same mode spacing of 7 FSR. These two groups of modes are spaced by 1 FSR. The recorded autocorrelator trace is plotted in figure 6a. Five pulses of $1.5 \mathrm{ps}$ width can be clearly observed in the 28ps roundtrip time. The recorded and calculated autocorrelation signals are presented in figure 6(a) and 6(b). Again these are matching well, which demonstrates the stable phase relation between the modes.

\section{Conclusion}

We have fabricated integrated modelocked ring lasers with active-passive integration. First experiments show that pulses down to $1.2 \mathrm{ps}$ width can be produced in bi-directional operation of the ringlaser with a fundamental repetition rate of 26 and 35Ghz. The autocorrelation traces of the output of the devices have been simulated using the output spectral data, demonstrating the locked phases of the modes. The investigation of these devices is ongoing and is focussing on the explanation of the observed mode structure, the achievement of operation at the fundamental repetition rate and on the behaviour of the device when injection seeded.

This research is supported by the Towards Freeband Communication Impulse of the technology programme of the Ministry of Economic Affairs of the Netherlands.

\section{References}

[1] J.H. den Besten, R.G. Broeke, M. van Geemert, J.J.M. Binsma, F. Heinrichsdorff, T. van Dongen, E.A.J.M. Bente, X.J.M. Leijtens, and M.K. Smit, "Compact digitally tunable seven-channel ring laser," PTL 14, 753-755 (2002)

[2] R.G. Broeke, J.J.M Binsma, M. van Geemert, F. Heinrichsdorff, T. van Dongen, J.H.C. van Zantvoort, X.J.M. Leijtens, Y.S. Oei, and M.K. Smit, "An all-optical wavelength converter with a monolithically integrated digitally tunable laser," in Proc. ECOC'02, PD 3.2 (2002)

[3] J. Leuthold, R. Hess, J. Eckner, P. A. Besse, and H. Melchior "Spatial mode filters realized with multimode interference couplers", Opt. Lett. 21, 836-838 (1996)

[4] J.J.M. Binsma, M. van Geemert, F. Heinrichsdorf, T. van Dongen, R.G. Broeke, and M.K. Smit, "MOVPE waveguide regrowth in InGaAsP/InP with extremely low butt joint loss," in Proc. IEEE/LEOS Symp. Benelux Chap. (2001)

[5] R.G. Broeke "A wavelength converter integrated with a dicretely tunable laser for wavelength division multiplexing networks" Ph.D Thesis Delft Univ. of Tech. (2002) 